\title{
PERILAKU KELUARGA DALAM MENDUKUNG MANAJEMEN HIPERTENSI DI KABUPATEN JEMBER
}

\author{
Sri Wahyuni Adriani \\ Universitas Muhammadiyah Jember, Fakultas Ilmu Kesehatan, Program Studi D3 \\ Keperawatan, Email: sriwahyuni@unmuhjember.ac.id
}

\begin{abstract}
ABSTRAK
Hipertensi memberikan dampak negatif terhadap fisik, psikologis, ekonomi dan sosial. Oleh sebab itu hipertensi membutuhkan perawatan yang optimal melalui manajemen hipertensi baik farmakologis maupun non farmakologis. Manajemen hipertensi tidak dapat dilakukan sendiri oleh pasien, sehingga membutuhkan dukungan dari keluarga. Tujuan penelitian ini adalah mengetahui perilaku keluarga dalam mendukung manajemen hipertensi. Metode penelitian yang digunakan yaitu deskriptif dengan jumlah sampel 55 klien hipertensi beserta keluarga yang merawatnya. Penelitian dilakukan bulan Februari hingga April tahun 2018. Hasil menunjukkan bahwa rata-rata keluarga mempunyai dukungan yang baik dalam merawat klien hipertensi. Bentuk dukungan yang paling banyak dilakukan keluarga adalah dukungan emosional, diikuti dengan dukungan informasi serta dukungan instrumental, kemudian dukungan penghargaan. Bentuk positif dukungan keluarga memberikan pengaruh terhadap keberhasilan manajemen hipertensi. Bantuan yang diberikan oleh anggota keluarga memberikan kenyamanan fisik dan psikologis pada seseorang yang dihadapkan pada situasi stress dalam hal ini klien hipertensi.
\end{abstract}

Kata Kunci: Perilaku Keluarga, Dukungan Keluarga, Manajemen Hipertensi

\begin{abstract}
Hypertension has a negative impact on physical, psychological, economic and social. Therefore hypertension requires optimal care through management of both pharmacological and non-pharmacological hypertension. Management of hypertension cannot be done alone by the patient, so it requires support from the family. The purpose of this study was to determine family behavior in supporting management of hypertension. The research method used was descriptive with a sample of 55 hypertensive clients and their families. The study was conducted in February to April 2018. The results showed that the average family had good support in treating hypertensive clients. The form of support that most families do were emotional support, followed by information support and instrumental support, then award support. The positive form of family support influences the success of hypertension management. Assistance provided by family members provides physical and psychological comfort to someone who is faced with a stressful situation in this case hypertensive clients.
\end{abstract}

Keywords: Family Behavior, Family Support, Hypertension Management 


\section{LATAR BELAKANG}

Badan Kesehatan Dunia atau The World Health Organization (WHO) melaporkan bahwa angka kejadian hipertensi terjadi peningkatan yang signifikan setiap tahunnya. Tahun 2010 hampir 7,5 juta orang meninggal karena penyakit hipertensi dan komplikasinya atau berkontribusi sekitar $12,5 \%$ dari total kematian di dunia. Sedangkan pada tahun 2013 WHO mencatat ada 1,5 miliar orang di dunia menderita hipertensi pada usia diatas 20 tahun. Pada tahun 2025, diproyeksikan sekitar 29\% populasi dewasa di dunia terkena hipertensi (Gusman, 2013).

Indonesia juga mengalami kondisi yang sama, di mana prevalensi hipertensi mengalami peningkatan tiap tahunnya. Tahun 2007 prevalensi hipertensi sebesar $7,6 \%$ dan meningkat menjadi $9,5 \%$ pada tahun 2013. Sedangkan pada kelompok usia di atas 18 tahun prevalensinya meningkat dari tahun 2007 sebesar 7,8\% menjadi $26,5 \%$ di tahun 2013 atau terjadi peningkatan sebesar $18,7 \%$ selama 6 tahun dan diperkirakan setiap tahunnya meningkat sebesar 3\%.

Berdasarkan Profil Kesehatan Provinsi Jawa Timur tahun 2012 dilaporkan bahwa hipertensi menempati peringkat pertama untuk kategori sepuluh penyakit terbanyak pasien rawat jalan pada rumah sakit tipe C (42.212 kasus). Di rumah sakit tipe $\mathrm{D}$ juga menempati peringkat pertama dengan 3.301 kasus. Selain itu hipertensi juga menempati urutan kedua penyakit terbanyak pasien rawat inap di rumah sakit tipe A sejumlah 12.590 kasus. Kabupaten Jember turut menyumbang angka tingginya prevalensi hipertensi di
Jawa Timur. Menurut Profil Dinas Kesehatan Kabupaten Jember tahun 2016 Kasus hipertensi di Kabupaten Jember merupakan peringkat kedua penyakit terbanyak yaitu sebesar $5,11 \%$ yang menjadi penyebab kunjungan terbanyak di seluruh Puskesmas Kabupaten Jember, sedangkan di rumah sakit yang bersifat rawat jalan, kejadian hipertensi sebesar 18,23\%.

Tingginya angka kejadian hipertensi akan mempengaruhi derajat kesehatan masyarakat. Hipertensi memberikan dampak negatif terhadap fisik, psikologis, ekonomi dan sosial. Hipertensi memiliki dampak yang signifikan pada peningkatan risiko penyakit kronis dan dinyatakan bahwa hipertensi meningkatkan risiko infark myocard, penyakit ginjal, stroke dan gagal jantung (Kabacki, 2010). Hipertensi persisten dapat mengarah pada kondisi gagal ginjal terminal atau End Stage Renal Failure (ESRF) dimana $80-90 \%$ pasien diharuskan menjalani cuci darah (Whitworth, 2005). Black \& Hawks (2014) menyatakan hipertensi merupakan faktor resiko utama untuk terjadinya masalah kesehatan seperti stroke, infark miokard, gagal jantung, aneurisma arteri, penyakit arteri perifer dan penyakit ginjal kronik.

Penelitian yang dilakukan oleh Strawbridge, Shema dan Roberts (2004) menyatakan masalah lain yang terjadi pada pasien hipertensi diantaranya gangguan tidur, kesehatan yang buruk, ketidakstabilan mood, tidak bahagia dan harga diri rendah. Akibat yang terjadi pada keluarga dengan pasien hipertensi berhubungan dengan sosial, ekonomi, fisik dan beban mental. Beban ini membuat keluarga mengatur kembali kebutuhan 
mereka. Keluarga dapat mengalami penurunan kepuasan terhadap hubungan, kesulitan dengan keintiman, pengungkapan kritik dan menunjukkan perilaku terlalu melindungi pasien (Goldberg \& Rickler, 2011). Anggota keluarga yang merawat pasien dengan hipertensi juga menghadapi aspek psikologis yang kurang baik seperti depresi dan kecemasan. Oleh karena itu, sebagai anggota keluarga merawat pasien merupakan salah satu tugas utama keluarga.

Tingkat dukungan keluarga secara signifikan terkait dengan penurunan tekanan darah (Connel \& Moseley, 2005). Hasil penelitian kualitatif oleh Widihastuti (2010) menyatakan bahwa banyak orang yang tidak mengubah pola diet, meskipun mereka sudah terdiagnosa hipertensi. Alasan yang menyebabkan pasien tidak mengubah perilakunya adalah kurangnya perhatian dari keluarga mengenai manajemen hipertensi. Oleh karena itu, keluarga diperlukan untuk membantu pasien dalam menerapkan manajemen nonfarmakologis hipertensi.

\section{METODE PENELITIAN}

Metode penelitian yang digunakan yaitu metode deskriptif yang bertujuan untuk melihat gambaran perilaku keluarga dalam mendukung manajemen hipertensi terhadap anggota keluarganya yang mengalami hipertensi. Populasi yang ditargetkan dalam penelitian ini adalah keluarga yang memiliki anggota keluarga dengan hipertensi di wilayah kerja puskesmas sukowono yang berjumlah kurang lebih 55 kasus (kunjungan bulan terakhir Januari 2018). Setelah dilakukan perhitungan sampel dengan rumus Slovin, maka didapatkan jumlah sampel target yaitu minimal 50 keluarga yang memiliki anggota keluarga dengan hipertensi.

Penelitian dilakukan di wilayah Kerja Puskesmas Sukowono Kabupaten Jember. Pelaksanaan penelitian dilakukan dari bulan Februari sampai dengan April 2018. Dalam prosesnya, penelitian ini menggunakan pertimbangan etik yaitu beneficence, respect to person, dan justice. Instrumen yang digunakan dalam penelitian ini adalah kuesioner. Analisis data penelitian menggunakan analisis univariat. Semua data dianalisis menggunakan proporsi frekuensi dan disajikan dalam bentuk distribusi frekuensi atau persentase.

\section{HASIL}

Hasil yang diperoleh dari 50 responden dan keluarga yang telah berpartisipasi dalam penelitian ini sebagai berikut:

Tabel 1: Distribusi Penderita Hipertensi Berdasarkan Usia (Tahun) di Desa Sumber Waru Kecamatan Sukowono Kabupaten Jember Tahun 2018 (n=50)

\begin{tabular}{ccccc}
\hline Mean & $\begin{array}{c}\text { Standar } \\
\text { Deviasi }\end{array}$ & Minimum & Maksium & $95 \%$ CI \\
\hline 58,12 & 9,570 & 37 & 78 & $55,40-60,84$ \\
\hline
\end{tabular}


Berdasarkan tabel 1 diketahui bahwa rerata usia penderita hipertensi dalam penelitian ini adalah 58 tahun dengan usia terendah 37 tahun dan tertinggi 78 tahun. Dari hasil estimasi interval, dapat disimpulkan bahwa 95\% diyakini rerata usia penderita hipertensi dalam penelitian ini berkisar antara usia 55 tahun hingga 61 tahun.

Tabel 2: Distribusi Penderita Hipertensi Berdasarkan Jenis Kelamin, Tingkat Pendidikan, Pekerjaan, dan Riwayat Hipertensi dalam Keluarga di Desa Sumber Waru Kecamatan Sukowono Kabupaten Jember Tahun $2018(\mathrm{n}=50)$

\begin{tabular}{|c|c|c|}
\hline \multirow{2}{*}{\multicolumn{3}{|c|}{$\begin{array}{l}\text { Variabel } \\
\text { Jenis Kelamin: }\end{array}$}} \\
\hline & & \\
\hline 1. Laki-laki & 9 & 18 \\
\hline 2. Perempuan & 41 & 82 \\
\hline \multicolumn{3}{|l|}{ Tingkat Pendidikan: } \\
\hline 1. Tidak Tamat SD/Tidak sekolah & 30 & 60 \\
\hline 2. Tamat SD & 17 & 34 \\
\hline 3. Tamat SMP & 2 & 4 \\
\hline 4. Tamat SMA & 1 & 2 \\
\hline 5. Perguruan Tinggi & 0 & 0 \\
\hline \multicolumn{3}{|l|}{ Pekerjaan: } \\
\hline 1. Petani & 26 & 52 \\
\hline 2. Buruh Tani & 9 & 18 \\
\hline 3. Wiraswasta & 4 & 8 \\
\hline 4. Ibu Rumah Tangga & 4 & 8 \\
\hline 5. Tidak Bekerja & 7 & 14 \\
\hline \multicolumn{3}{|l|}{ Pendapatan: } \\
\hline 1. Dibawah UMR & 40 & 80 \\
\hline 2. Diatas UMR & 10 & 20 \\
\hline \multicolumn{3}{|l|}{$\begin{array}{lll}\text { Riwayat } & \text { Hipertensi } & \text { dalam } \\
\text { Keluarga: } & & \end{array}$} \\
\hline 1. Ada & 31 & 62 \\
\hline 2. Tidak ada & 19 & 38 \\
\hline
\end{tabular}

Dari tabel 2 diketahui bahwa karakteristik penderita hipertensi dalam penelitian ini berdasarkan jenis kelamin paling banyak adalah perempuan sebesar 82\%, tingkat pendidikan mayoritas tidak tamat SD/tidak sekolah sebesar 60\%, pekerjaan paling banyak petani sejumlah $52 \%$, dan riwayat hipertensi dalam keluarga paling banyak memiliki riwayat hipertensi dalam keluarga sebesar $62 \%$.

Tabel 3: Distribusi Karakteristik Keluarga Berdasarkan Usia (Tahun) di Desa Sumber Waru Kecamatan Sukowono Kabupaten Jember Tahun 2018 (n=50)

\begin{tabular}{ccccc}
\hline Mean & $\begin{array}{c}\text { Standar } \\
\text { Deviasi }\end{array}$ & Minimum & Maksium & $95 \%$ CI \\
\hline 47,14 & 9,328 & 32 & 69 & $44,49-49,79$ \\
\hline
\end{tabular}


Berdasarkan tabel 3 diketahui bahwa rerata usia keluarga yang merawat penderita hipertensi dalam penelitian ini adalah 47 tahun dengan usia terendah 32 tahun dan tertinggi 69 tahun. Dari hasil estimasi interval, dapat disimpulkan bahwa 95\% diyakini rerata usia keluarga yang merawat penderita hipertensi dalam penelitian ini berkisar antara usia 44 tahun hingga 50 tahun.

Tabel 4: Distribusi Karakteristik Keluarga Berdasarkan Jenis Kelamin, Tingkat Pendidikan dan Pekerjaan di Desa Sumber Waru Kecamatan Sukowono Kabupaten Jember Tahun $2018(\mathrm{n}=50)$

\begin{tabular}{lcc}
\hline \multicolumn{1}{c}{ Variabel } & Frekuensi & Persentase (\%) \\
\hline Jenis Kelamin: & 22 & \\
1. Laki-laki & 28 & 44 \\
2. Perempuan & & 56 \\
\hline Tingkat Pendidikan: & 6 & \\
1. Tidak Tamat SD/Tidak sekolah & 35 & 12 \\
2. Tamat SD & 8 & 70 \\
3. Tamat SMP & 1 & 16 \\
4. Tamat SMA & 0 & 2 \\
5. Perguruan Tinggi & & 0 \\
\hline Pekerjaan: & 13 & \\
1. Petani & 5 & 26 \\
2. Buruh Tani & 8 & 10 \\
3. Wiraswasta & 24 & 16 \\
4. Ibu Rumah Tangga & & 48 \\
\hline
\end{tabular}

Dari tabel 4 diketahui bahwa karakteristik keluarga yang merawat penderita hipertensi dalam penelitian ini berdasarkan jenis kelamin paling banyak adalah perempuan sebesar 56\%, tingkat pendidikan mayoritas tamat SD sebesar 70\%, pekerjaan paling banyak ibu rumah tangga sejumlah $48 \%$.

Tabel 5: Distribusi Perilaku Penderita Hipertensi dalam Melakukan Perawatan Hipertensi di Desa Sumber Waru Kecamatan Sukowono Kabupaten Jember Tahun $2018(n=50)$

\begin{tabular}{lcc}
\hline $\begin{array}{l}\text { Perilaku Penderita Hipertensi dalam } \\
\text { Melakukan Perawatan Hipertensi }\end{array}$ & Frekuensi & Persentase (\%) \\
\hline Baik atau Berperilaku Sehat & 24 & 48 \\
\hline $\begin{array}{l}\text { Kurang Baik atau Berperilaku Tidak } \\
\text { Sehat }\end{array}$ & 26 & 52 \\
\hline
\end{tabular}

Berdasarkan tabel diketahui bahwa rata-rata penderita hipertensi dalam penelitian ini mempunyai perilaku kurang baik dalam melakukan perawatan hipertensi atau mempunyai perilaku tidak sehat sebesar $52 \%$. 
Tabel 6: Distribusi Tingkat Kepatuhan Penderita Hipertensi dalam Melakukan Perawatan Hipertensi di Desa Sumber Waru Kecamatan Sukowono Kabupaten Jember Tahun $2018(\mathrm{n}=50)$

\begin{tabular}{|c|c|c|}
\hline $\begin{array}{c}\text { Tingkat Kepatuhan Penderita } \\
\text { Hipertensi dalam Melakukan } \\
\text { Perawatan Hipertensi }\end{array}$ & Frekuensi & Persentase $(\%)$ \\
\hline \multicolumn{3}{|l|}{ Makan buah setiap hari } \\
\hline 1. Iya & 7 & 14 \\
\hline 2. Tidak & 43 & 86 \\
\hline \multicolumn{3}{|l|}{ Makan sayur setiap hari } \\
\hline 1. Iya & 46 & 92 \\
\hline 2. Tidak & 4 & 8 \\
\hline \multicolumn{3}{|l|}{ Makan makanan cepat saji } \\
\hline 1. Iya & 7 & 14 \\
\hline 2. Tidak & 43 & 86 \\
\hline \multicolumn{3}{|l|}{ Makan makanan asin } \\
\hline 1. Iya & 12 & 24 \\
\hline 2. Tidak & 38 & 76 \\
\hline \multicolumn{3}{|l|}{$\begin{array}{l}\text { Makan makanan berlemak/tinggi } \\
\text { kolesterol }\end{array}$} \\
\hline 1. Iya & 11 & 22 \\
\hline 2. Tidak & 39 & 78 \\
\hline \multicolumn{3}{|l|}{ Merokok } \\
\hline 1. Iya & 7 & 14 \\
\hline 2. Tidak & 43 & 86 \\
\hline \multicolumn{3}{|l|}{$\begin{array}{l}\text { Minum minuman beralkohol atau } \\
\text { mengandung kafein }\end{array}$} \\
\hline 1. Iya & 17 & 34 \\
\hline 2. Tidak & 33 & 66 \\
\hline \multicolumn{3}{|l|}{ Tidur teratur } \\
\hline 1. Iya & 20 & 40 \\
\hline 2. Tidak & 30 & 60 \\
\hline \multicolumn{3}{|l|}{ Olahraga } \\
\hline 1. Iya & 41 & 82 \\
\hline 2. Tidak & 9 & 18 \\
\hline \multicolumn{3}{|l|}{ Minum air putih yang cukup } \\
\hline 1. Iya & 43 & 86 \\
\hline 2. Tidak & 7 & 14 \\
\hline
\end{tabular}

Berdasarkan tabel diketahui bahwa mayoritas penderita hipertensi dalam penelitian ini tidak makan buah setiap hari yaitu $86 \%$, perilaku makan sayur setiap hari sudah baik yaitu $92 \%$, masih ada penderita yang suka makan makanan cepat saji meskipun hanya $14 \%$, terdapat $24 \%$ penderita masih makan makanan asin dan $22 \%$ masih suka makan makanan tinggi lemak/kolesterol tinggi, terdapat $14 \%$ penderita hipertensi masih merokok dan $34 \%$ masih minum minuman yang mengandung kafein dan alkohol, mayoritas penderita hipertensi tidak tidur teratur sejumlah $60 \%$, sedangkan perilaku olahraga dan minum air putih yang cukup 
sudah baik yaitu mayoritas melakukan olahraga secara teratur sebesar $82 \%$ dan minum air putih yang cukup sebesar $86 \%$.

Tabel 7: Distribusi Dukungan Keluarga dalam Perawatan Hipertensi di Desa Sumber Waru Kecamatan Sukowono Kabupaten Jember Tahun 2018 (n=50)

\begin{tabular}{lcc}
\hline $\begin{array}{c}\text { Dukungan Keluarga dalam } \\
\text { Perawatan Hipertensi }\end{array}$ & Frekuensi & Persentase (\%) \\
\hline Dukungan keluarga baik & 26 & 52 \\
\hline Dukungan keluarga kurang & 24 & 48 \\
\hline
\end{tabular}

Berdasarkan tabel 7 diketahui bahwa rata-rata keluarga dalam penelitian ini mempunyai dukungan yang baik dalam merawat anggota keluarganya yang mengalami hipertensi sebesar 52\%.

Tabel 8: Distribusi Bentuk Dukungan Keluarga dalam Perawatan Hipertensi di Desa Sumber Waru Kecamatan Sukowono Kabupaten Jember Tahun 2018 (n=50)

\begin{tabular}{lcc}
\hline $\begin{array}{c}\text { Bentuk Dukungan Keluarga dalam } \\
\text { Perawatan Hipertensi }\end{array}$ & Frekuensi & Persentase (\%) \\
\hline Dukungan emosional & & \\
1. Iya & 36 & 72 \\
2. Tidak & 14 & 28 \\
\hline Dukungan penghargaan & & \\
$\quad$ 1. Iya & 26 & 52 \\
2. Tidak & 24 & 48 \\
\hline Dukungan informasi & & \\
1. Iya & 27 & 54 \\
2. Tidak & 23 & 46 \\
\hline Dukungan instrumental & & \\
1. Iya & 27 & 54 \\
2. Tidak & 23 & 46 \\
\hline
\end{tabular}

Tabel 8 menunjukkan bahwa bentuk dukungan yang paling banyak dilakukan keluarga adalah dukungan emosional sebesar $72 \%$, diikuti dengan dukungan informasi serta dukungan instrumental dengan hasil yang sama yaitu sebesar 54\%, kemudian dukungan penghargaan sebesar $52 \%$.

\section{PEMBAHASAN}

Dari segi usia, jumlah penderita hipertensi dalam penelitian ini paling banyak berada dalam rentang usia 55 tahun hingga 61 tahun. Kategori usia tersebut adalah dewasa akhir. Karakteristik usia penderita hipertensi dalam penelitian ini tidak berbeda dengan hasil penelitian Laili (2016) yang menemukan bahwa kejadian hipertensi dalam penelitiannya secara keseluruhan dari kelompok kasus dan kontrol paling banyak terjadi pada usia $\geq 55$ tahun. Kudo, et. al (2015) juga menemukan bahwa karakteristik usia pasien hipertensi di Tokyo, Jepang rata-rata berusia 57 tahun. Berdasarkan Riskesdas (2013) 
prevalensi hipertensi meningkat dengan bertambahnya umur, dimana umur 65-74 tahun prevalensinya sebesar 57,6\%, umur 75 tahun keatas prevalensinya meningkat sampai 63,8\%. Didukung penelitian Fitria dan Marissa (2016) yang menemukan bahwa seseorang pada umur 55-90 tahun mempunyai risiko hampir 4 kali untuk terkena hipertensi dibandingkan umur 18-54 tahun. Hasil ini sesuai dengan teori yang menyebutkan bahwa faktor umur berpengaruh terhadap kejadian hipertensi, dimana semakin tua seseorang, maka semakin besar risiko terserang hipertensi. Hal ini disebabkan oleh menurunnya elastisitas pembuluh darah arteri (Bucher, et.al, 2014).

Karakteristik penderita hipertensi dilihat dari jenis kelamin dalam penelitian ini ditemukan bahwa mayoritas berjenis kelamin perempuan. Hasil ini sesuai dengan penelitian Hung, et.al (2014) di China yang menemukan bahwa mayoritas penderita hipertensi adalah perempuan. Didukung oleh penelitian Yeni, et.al (2016) menunjukkan bahwa mayoritas penderita hipertensi yang menjadi repsonden dalam penelitiannya adalah perempuan. Fitria dan Marissa (2016) menemukan bahwa jenis kelamin memiliki peluang 1,13 kali untuk terkena hipertensi dari pada laki-laki. Kondisi ini terjadi karena berkaitan dengan menurunnya sistem hormon pada wanita seiring dengan bertambahnya usia. Perempuan memiliki hormon esterogen yang mampu mempertahankan kekebalan tubuh sampai usia menopause sebagai pelindung dalam proses aterosklerosis (Bushell, 2009). Dengan bertambahnya usia, maka hormon estrogen menurun sehingga perlindungan terhadap terjadinya aterosklerosis juga mengalami penurunan. Wanita pada masa monopause cenderung memiliki tekanan darah lebih tinggi dari pria. Penyebabnya adalah sebelum menopause wanita relatif terlindung dari penyakit ardiovaskuler oleh hormon estrogen, namun kadar estrogen menurun setelah menopause. Penurunan produksi estrogen akan meningkatkan kadar LDL kolesterol yang akan menyumbat pembuluh darah sehingga aliran darah tidak lancar karena pembuluh darah menyempit menyebabkan tekanan pada pembuluh darah akan meninggi (Bucher, et.al, 2009).

Namun berbeda dengan hasil penelitian Kudo, at.al (2015) yang menunjukkan bahwa mayoritas penderita hipertensi di Jepang berjenis kelamin laki-laki. Penelitian Sugiarta dan Sutriyasa (2013) juga menemukan bahwa mayoritas penderita hipertensi yang dirawat di RS adalah laki-laki. Laili (2017) juga menemukan bahwa mayoritas penderita stroke yang diakibatkan oleh hipertensi berjenis kelamin lakilaki. Selain itu, data NCHS (National Center of Health Statistic) juga menyebutkan bahwa prevalensi hipertensi sama pada laki-laki dan perempuan di Amerika Serikat tahun 2011-2012. Kondisi ini didukung oleh pernyataan Bushnell (2009) bahwa kejadian penyakit degeneratif seperti hipertensi yang berlanjut pada stroke banyak dialami oleh laki-laki karena laki-laki memiliki hormon testoteron yang bisa meningkatkan kadar LDL darah, apabila kadar LDL tinggi akan meningkatkan kadar kolesterol dalam darah, jika kolesterol dalam darah meningkat 
akan meningkatkan risiko penyakit degeneratif karena kolesterol darah tinggi merupakan salah satu faktor risiko penyebab penyakit degeneratif (Watila, et.al, 2010). Dengan demikian, baik lelaki maupun perempuan sama-sama memiliki proporsi yang tinggi menderita hipertensi seiring dengan bertambahnya usia.

Dilihat dari segi tingkat pendidikan, penderita hipertensi dalam penelitian ini mayoritas berpendidikan rendah. Hasil yang sama juga ditemukan pada penelitian Mordiana dan Weta (2014) yang menunjukkan bahwa mayoritas penderita hipertensi memiliki pendidikan rendah. Bisnu, et.al (2017) juga menemukan bahwa mayoritas pendeita hipertensi di Puskemas berpendidikan rendah. Penelitian Dewi, et.al (2016) juga menemukan bahwa mayoritas penderita hipertensi berpendidikan rendah. Rosiana (2014) juga menyatakan prevalensi hipertensi cendrung lebih tinggi pada kelompok pendidikan lebih rendah akibat ketidaktahuan tentang pola makan yang baik, tingkat pendidikan berpengaruh terhadap gaya hidup sehat dengan tidak merokok, tidak minum alkohol, dan lebih sering berolahraga. Fitria dan Marissa (2016) menyatakan bahwa pendidikan rendah berisiko 5,6 kali untuk menderita hipertensi dibandingkan dengan mereka yang memiliki tingkat pendidikan menengah dan tinggi. Adapun pendidikan menengah berpeluang 2,1 kali menderita hipertensi, ini artinya kemungkinannya lebih kecil dari mereka yang berpendidikan rendah. Mereka berpendapat bahwa faktor pendidikan memiliki peranan penting dalam kehidupan seseorang.
Kejadian hipertensi dalam masyarakat miskin terjadi karena kurangnya pengetahuan masyarakat tentang hipertensi. Pengetahuan tentang kesehatan akan berpengaruh terhadap perilaku sebagai hasil jangka menengah dari pendidikan kesehatan.

Karakteristik pekerjaan
berhubungan erat dengan
pendapatan. Berdasarkan hasil dapat dilihat bahwa mayoritas penderita hipertensi bekerja sebagai petani yang memiliki pendapatan dibawah UMR. Hasil penelitian ini sesuai dengan penelitian Iskandar, et.al (2012) bahwa mayoritas penderita hipertensi adalah buruh/petani/nelayan yang memiliki penghasilan dibawah UMR atau kategori miskin. Tidak sekolah cenderung tidak bekerja, sekalipun bekerja tidak mendapatkan penghasilan yang besar. Golongan ini diduga memiliki tekanan psikis yang lebih besar dari lingkungan sekitar. Rasa tertekan (depresi) berhubungan dengan kejadian hipertensi (Yan et al, 2003).

Karakteristik dilihat dari adanya riwayat hipertensi dalam keluarga ditemukan hasil bahwa mayoritas penderita hipertensi memang memiliki riwayat hipertensi dalam keluarganya. Hasil ini didukung oleh pendapat Bucher, et.al (2009) bahwa hipertensi merupakan penyakit degeneratif, artinya dapat diturunkan dari keluarga. Sudoyo, et.al (2009) juga mendukung konsep tersebut yang menyatakan bahwa hipertensi dapat diturunkan sehingga seseorang yang dalam keluarganya memiliki riwayat hipertensi kemungkinan besar akan memiliki peluang lebih tinggi untuk mengalami hipertensi. 
Berdasarkan hasil penelitian diketahui bahwa mayoritas perilaku penderita hipertensi dalam penelitian ini adalah kurang baik atau perilaku tidak sehat. Kondisi ini dibuktikan dengan hasil yang menunjukkan bahwa penderita hipertensi dalam penelitian ini tidak makan buah setiap hari, masih ada penderita yang suka makan makanan cepat saji, penderita masih makan makanan asin dan masih suka makan makanan tinggi lemak/kolesterol tinggi, penderita hipertensi masih merokok dan masih minum minuman yang mengandung kafein dan alkohol, mayoritas penderita hipertensi tidak tidur teratur. Hasil ini sesuai dengan penelitian Yusuf (2013) yang menemukan bahwa gambaran praktik atau tindakan penderita hipertensi dalam upaya mencegah kekambuhan ulang penyakit hipertensi mayoritas masih kurang dikarenakan kurangnya kesadaran dari responden akan pentingnya upaya mencegah kekambuhan penyakit hipertensi dan sulitnya meluangkan waktu untuk memeriksakan diri ke pelayanan kesehatan dan mengikuti penyuluhan kesehatan yang diberikan oleh petugas kesehatan. Berdasarkan hasil penelitian tersebut juga didapatkan sebagian responden memiliki tindakan yang kurang baik dalam upaya mencegah kekambuhan penyakit hipertensi, seperti jarang mengukur tekan darah dan mengonsumsi buah dan sayur setiap hari. Responden paling banyak tidak pernah menghindari makanan berkolestrol tinggi dan mengandung garam tinggi, minum obat antihipertensi secara teratur, beristirahat walaupun pekerjaan menumpuk, berolahraga secara teratur, rekreasi dan mengontrol emosi jika sedang marah sebagai upaya mencegah kekambuhan penyakit hipertensi.

Didukung dengan hasil penelitian Kudo, at.al (2016) di Jepang yang menemukan bahwa untuk gaya hidup penderita hipertensi mayoritas partisipan menyatakan tidak merokok dalam kesehariannya, tidak mengonsumsi minuman beralkohol, dan mengkonsumsi snack diantara jam makan. Namun ternyata masih ada penderita hipertensi yang kurang melakukan aktivitas fisik yang dianjurkan dan memiliki BMI di atas batas normal. Hasil penelitian Quigley, et.al (2015) juga menemukan bahwa perilaku pasien yang didiagnosis hipertensi rata-rata sudah baik yang dibuktikan dengan perubahan perilaku sehat seperti menjaga diet dengan cara latihan. Semua partisipan menyatakan mulai diet dengan makanan tradisional dibandingkan dengan makanan cepat saji, namun masih terdapat partisipan terutama yang berjenis kelamin lakilaki masih mengonsumi alkohol dan merokok. Meskipun dokter telah menganjurkan untuk berhenti minum alkohol dan merokok, namun beberapa partisipan merasa kesulitan untuk berhenti karena mempunyai kebiasaan minum bersama pasangan dan teman. Semua partisipan sudah mengurangi konsumsi garam, namun terdapat beberapa partisipan masih merasa kesulitan dalam pengaturan latihan.

Risiko yang akan terjadi pada penderita hipertensi yang tidak menjaga perilakunya dengan baik adalah sulit untuk sembuh, jika sudah sembuh maka risiko kekambuhan dari penyakitnya akan semakin tinggi, dan yang paling ditakutkan adalah terjadinya stroke. Oleh sebab itu pentingnya menjaga 
perilaku atau melakukan perawatan bagi penderita hipertensi sangat diperlukan untuk mengurangi risiko negatif yang akan terjadi.

Hasil penelitian menunjukkan bahwa perilaku keluarga dalam mendukung perawatan hipertensi sudah baik. Dukungan keluarga dalam penelitian ini dilihat dari empat komponen yaitu dukungan emosional, dukungan penghargaan, dukungan informasi dan dukungan instrumental. Hasil ini sesuai dengan penelitian Bisnu (2017) bahwa keluarga memberikan dukungan yang baik dalam merawat pasien hipertensi. Didukung oleh penelitian Dewi, et, al (2016) bahwa dukungan keluarga dalam manajemen hipertensi dikategorikan cukup. Penelitian tersebut juga menyatakan bahwa diantara empat jenis dukungan keluarga yang ada, jenis dukungan keluarga yang paling dibutuhkan oleh responden adalah pada jenis dukungan informasional dengan hasil $r$ tabel tertinggi yaitu 436 dengan nilai signifikan 0,005. Penelitian Yeni, at.al (2016) juga menyatakan bahwa dukungan keluarga terhadap kepatuhan pasien hipertensi mayoritas kategori dukungan sedang. Firmansyah, et. al (2017) juga menemukan bahwa dukungan keluarga terhadap pencegahan primer hipertensi sudah baik, dibuktikan dengan pengetahuan keluarga mayoritas baik, dilihat dari dukungan spiritual keluarga mayoritas baik, dukungan emosional keluarga juga mayoritas baik, praktik keluarga dalam pencegahan primer hipertensi juga sudah baik.

Dukungan keluarga diartikan sebagai bantuan yang diberikan oleh anggota keluarga yang lain sehingga memberikan kenyamanan fisik dan psikologis pada seseorang yang dihadapkan pada situasi stress. Friedman, Bowden dan Jones (2003) menyatakan bahwa dukungan keluarga merupakan perilaku melayani yang dilakukan oleh keluarga baik dalam bentuk dukungan emosional, penghargaan/penilaian, informasional dan instrumental.

Keluarga merupakan suatu sistem, sebagai sistem keluarga mempunyai anggota yaitu ayah, ibu, kakak atau semua individu yang tinggal di dalam rumah. Masalah kesehatan yang dialami oleh salah satu anggota keluarga dapat mempengaruhi anggota keluarga yang lain dan seluruh sistem (Kaakinen, et.al, 2015). Keluarga berfungsi untuk mempertahankan keadaan kesehatan anggota keluarganya agar tetap memiliki produktifitas tinggi. Selain itu tugas keluarga dalam bidang kesehatan adalah kemampuan mengenal masalah kesehatan, kemampuan mengambil keputusan untuk mengatasi masalah kesehatan, kemampuan merawat anggota keluarga yang sakit, kemampuan memodifikasi lingkungan untuk keluarga agar tetap sehat dan optimal, serta kemampuan memanfaatkan sarana kesehatan yang tersedia di lingkunganya (Setiadi, 2008).

Menurut Osamor (2015), penyakit kronis seperti hipertensi membutuhkan pengobatan seumur hidup. Hal ini merupakan tantangan bagi pasien dan keluarga agar dapat mem-pertahankan motivasi untuk mematuhi pengo-batan selama bertahun-tahun. Salah satu cara untuk meningkatkan motivasi adalah melalui dukungan keluarga. Ketika keluarga berbagi masalahnya dengan sitem dukungan sosial maka saran 
dan bimbingan akan diberikan kepada klien. Menciptakan lingkungan yang penuh kasih sayang, mengarahkan dan menemukan sumber perawatan serta memberikan bantuan finansial merupakan bentuk umum dari dukungan keluarga. Menurut Osamor (2015), dukungan sosial akan meningkatkan kesadaran untuk menggunakan pelayanan kesehatan yang merupakan salah satu komponen penting dari kepatuhan.

Penatalaksanaan penyakit kronik seperti hipertensi membutuhkan dukungan keluarga yang adekuat. Memperluas dukungan keluarga tidak hanya terbatas pada pasangan atau anggota keluarga yang lainnya tetapi juga melibatkan keluarga lainnya (jaringan sosial keluarga) sangat dibutuhkan (Wilson \& Ampey-Thornhill, 2001). Sehingga dukungan keluarga yang baik akan sangat mempengaruhi perilaku penderita hipertensi dalam melakukan perawatan hipertensi.

\section{SIMPULAN}

Berdasarkan uraian yang telah dipaparkan maka dapat disimpulkan bahwa perilaku penderita hipertensi dalam melakukan manajemen atau perawatan hipertensi mayoritas masih kurang baik dengan gambaran tidak makan buah setiap hari yaitu $86 \%$, perilaku makan sayur setiap hari sudah baik yaitu $92 \%$, masih ada penderita yang suka makan makanan cepat saji meskipun hanya $14 \%$, terdapat $24 \%$ penderita masih makan makanan asin dan $22 \%$ masih suka makan makanan tinggi lemak/kolesterol tinggi, terdapat $14 \%$ penderita hipertensi masih merokok dan $34 \%$ masih minum minuman yang mengandung kafein dan alkohol, mayoritas penderita hipertensi tidak tidur teratur sejumlah $60 \%$, sedangkan perilaku olahraga dan minum air putih yang cukup sudah baik yaitu mayoritas melakukan olahraga secara teratur sebesar $82 \%$ dan minum air putih yang cukup sebesar $86 \%$. Perilaku keluarga dalam mendukung manajemen hipertensi mayoritas sudah baik dengan gambaran dukungan yang paling banyak dilakukan keluarga adalah dukungan emosional sebesar $72 \%$, diikuti dengan dukungan informasi serta dukungan instrumental dengan hasil yang sama yaitu sebesar 54\%, kemudian dukungan penghargaan sebesar $52 \%$.

\section{SARAN}

\section{Puskesmas}

Hasil penelitian ini diharapkan dapat menjadi acuan atau dasar dalam menyusun program di puskesmas khususnya dalam program kunjungan keluarga agar mengoptimalkan dukungan keluarga untuk meningkatkan perawatan pada penderita hipertensi.

\section{Dinas Kesehatan}

Dinas Kesehatan sebagai koordinator utama dalam setiap kegiatan Puskesmas diharapkan dapat melakukan follow up secara berkala terkait kunjungan keluarga yang berjalan di puskesmas untuk mengoptimalkan jumlah kunjungan keluarga yang dilakukan oleh Puskesmas.

\section{Peneliti Selanjutnya}

Hasil dari penelitian ini diharapkan dapat menjadi acuan bagi peneliti selanjutnya untuk melakukan penelitian mengenai kaitan dukungan keluarga dengan perilaku penderita 
hipertensi dalam melakukan perawatan hipertensi.

\section{DAFTAR PUSTAKA}

Bisnu, M.I.K. (2017). Hubungan Dukungan Keluarga Dengan Derajat Hipertensi Pada Pasien Hipertensi Di Puskesmas Ranomuut Kota Manado. $e$ Journal Keperawatan (e-KP). Volume 5 Nomor 1

Bucher,Heitkemper,Dirksen dan Lewis (2014). Assesment and Management of Clinical Problem. St.Louis Missouri: Elsevier.

Dewi, K.C.C, Prapti, N.KG \& Saputra, I.K. (2016). Hubungan Dukungan Keluarga Dengan Tingkat Kepatuhan Penatalaksanaan Diet Lansia Dengan Hipertensi Di Lingkungan Kelurahan Tonja. Jurnal Keperawatan Community of Publishing in Nursing COPING) NERS. ISSN: 2303-1298

Dinas Kesehatan Kabupaten Jember. (2015). Laporan profil kesehatan Kabupaten Jember. Jember: Author

Dinas Kesehatan Provinsi Jawa Timur. (2013). Profil kesehatan Provinsi Jawa Timur tahun 2012. Surabaya: Author

Dinas Kesehatan Provinsi Jawa Timur. (2014). Ringkasan eksekutif data dan informasi kesehatan Provinsi Jawa Timur. Surabaya: Pusdatin
Friedman, M.M. (2003). Family nursing: Research, theory, and practice. 5 the $^{\text {th }}$.Connecticut: Appleton \& Lange

Firmansyah, R.S, Lukman, M \& Mambangsari, C.W. (2017). Faktor-Faktor yang Berhubungan dengan Dukungan Keluarga dalam Pencegahan Primer Hipertensi. $J K P$ - Volume 5 Nomor 2 Agustus 2017

Fitria, E \& Marissa, N. (2016). Karakteristik Penderita Hipertensi pada Masyarakat Miskin Di Desa Ceurih Kecamatan Ulee Kareng Kota Banda Aceh. SEL Vol. 3 No. 2 November 2016: 64-70

Hung C-Y, Wang K-Y, Wu T-J, Hsieh Y-C, Huang J-L, et al. (2014) Resistant Hypertension, Patient Characteristics, and Risk of Stroke. PLOS ONE 9(8): $\quad$ e104362. doi:10.1371/journal.pone.0104 362

Kaakinen J R, Coehlo D P, Steele R, Tobacco A \& Hanson S M. (2015). Family health care nursing: Theory, practice, and research. Fifth edition. Philadelphia: Davis Company

Kabakci, et al. 2010. Global cardio metabolic risk profile in patients with hypertension: results from the Turkish arm of the pan-European GOOD survey. Türk Kardiyol Dern Arş - Arch Turk Soc Cordial 2010;38(5):313-320 
Kementerian Kesehatan RI, (2015). Pedoman umum pos pembinaan terpadu penyakit tidak menular. Jakarta : Kementerian Kesehatan RI

Kementerian Kesehatan Republik Indonesia. (2013). Laporan riset kesehatan dasar 2013. Jakarta: Badan Penelitian dan Pengembangan Kesehatan Kementerian Kesehatan Republik Indonesia

Kemenkes RI. (2014). Profil Kesehatan Indonesia 2013. Jakarta

Kudo N, Yokokawa H, Fukuda H, Sanada H, Miwa Y, Hisaoka T, et al. (2015) Achievement of Target Blood Pressure Levels among Japanese Workers with Hypertension and Healthy Lifestyle Characteristics Associated with Therapeutic Failure. PLoS ONE 10(7): e0133641. doi:10.1371/journal. pone. 0133641

Laily, S.R. (2017). Hubungan Karakteristik Penderita Dan Hipertensi Dengan Kejadian Stroke Iskemik. Jurnal Berkala Epidemiologi, Volume 5 Nomor 1, Januari 2017, hlm. 48-59. doi:10.20473/jbe.v5i1

Legido-Quigley H, Camacho Lopez PA, Balabanova D, Perel P, Lopez-Jaramillo P, Nieuwlaat R, et al. (2015). Patients' Knowledge, Attitudes, Behaviour and Health Care Experiences on the Prevention, Detection, Management and Control of Hypertension in Colombia: A Qualitative
Study. PloS ONE 10(4): e0122112. doi:10.1371/journal. pone.0122112

Mordiana, P.R \& Weta, I. W. (2014). Gambaran Perilaku Pasien Hipertensi Di Wilayah Kerja Puskesmas Banjarangkan Ii Kabupaten Klungkung Bali 2014. ISM, Vol. 8 No.1, Januari-Maret. ISSN: 20899084

Riley, J and G. Fenton. 2007. A terminal diagnosis: the carers' perspective. Counseling and Psychotherapy Research, June 2007; 7(2): 86-91

WHO, (2013). A global brief on hypertension : sillent killer : global public helath crisis. Geneva : WHO

World Health Organization. 2010. Global status report: on noncommunicable disease 2010. World Health Organization.

World Life Expectancy. 2011. World health ranking. Available Source: http://www.worldlifeexpectanc y.com/

Yeni, F, Husna, M \& Dachriyanus. (2016). Dukungan Keluarga Memengaruhi Kepatuhan Pasien Hipertensi. Jurnal Keperawatan Indonesia, Volume 19 No.3, November 2016, hal 137-144 pISSN 1410-4490, eISSN 2354-9203. DOI : 10.7454/jki.v19i3.471

Yusuf, D.Y.N. (2013). Gambaran Perilaku Penderita Hipertensi Dalam Upaya Mencegah 
Kekambuhan Penyakit

Hipertensi Di Wilayah Kerja

Puskesmas Dulalow Kota

Gorontalo Tahun 2013.

Program Studi Ilmu
Keperawatan, Fakultas Ilmuilmu Kesehatan dan Keolahragaan, Universitas Negeri Gorontalo. Skripsi yang tidak dipublikasikan 